\title{
THE INFLUENCE OF CORTICOSTEROIDS ON NORMAL AND PAPAIN-TREATED ARTICULAR CARTILAGE IN THE RABBIT
}

\author{
N. E. Shaw and Eve Lacey, Manchester, England \\ From the Department of Orthopaedic Surgery, University of Manchester
}

\begin{abstract}
Whether or not corticosteroids induce arthropathy has been a source of controversy for more than a decade. Pietrogrande and Mastromarino (1957) reported severe degeneration of the hip joint of a patient receiving these drugs. Progressive degenerative joint changes have been reported after systemic or intra-articular administration of steroids (Chandler and Wright 1958; Sweetnam, Mason and Murray 1960). On the other hand, distorted joints undoubtedly occur in progressive arthritis when corticosteroids have never been prescribed. Kendall (1958) and Moynihan (1962) have commented on the rarity of accelerated degenerative joint changes in patients given corticosteroids.

After administration of corticosteroids to patients suffering from arthritis, it is impossible to decide how much damage is due to the steroids and how much to the natural progress of the disease. It was thought possible to design an animal experiment that would throw some light on the matter. Normal knee joints of young rabbits have therefore been examined for their reaction to daily corticosteroids in very small doses comparable, when adjusted for body-weight, with those used clinically in patients. To test the effect of cortisone on the repair of damaged joints, a single dose of intravenous papain was given to another group of rabbits at the start of a series of daily steroid injections. Papain, a protease, splits the large chondromucoprotein molecules of cartilage, liberating the mucinous chondroitin sulphates and leaving a depleted matrix. This creates an artificial arthritis (Bentley 1971), the repair of which can be studied in the experimental animal. A comparison of animals receiving corticosteroids with normal or papain-treated controls should provide a useful indication of the clinical effects of these drugs on normal or diseased joints in man.
\end{abstract}

\section{MATERIALS AND METHODS}

Fifty-one New Zealand Red rabbits weighing 600-1,000 grammes were used in the following groups: Group 1) thirteen normal control animals, kept in cages with the experimental rabbits and killed at the same ages; Group 2) six rabbits given daily cortisone by intramuscular injection $(0 \cdot 1 \mathrm{milligram} / \mathrm{kilogram} /$ day $)$, and six rabbits given daily methyl prednisolone by intra-articular injection into the left knee $(0 \cdot 1 \mathrm{milligram} / \mathrm{kilogram} /$ day $)$; Group 3$)$ thirteen rabbits recovering from a single intravenous dose of papain (5 milligrams/kilogram); and Group 4) ten rabbits in which papain was followed by daily cortisone $(0.1 \mathrm{milligram} / \mathrm{kilogram} /$ day) (in six animals intramuscularly, in four intra-articularly to the left knee), and three rabbits in which papain was followed by daily methyl prednisolone $(0.1 \mathrm{milligram} / \mathrm{kilogram} /$ day $)$ intra-articularly to the left knee.

Tracer doses of $0.5 \mathrm{mc}$ of sulphur- 35 as sodium sulphate were given two days before death for autoradiography. The animals were killed at intervals to form a time series: Group 3, at twelve, eighteen and twenty-four hours, two, four, five, eight, thirteen, seventeen and twenty-two days after papain; Groups 2 and 4, after three, four, six, eight, thirteen, seventeen and twenty-one days of daily corticosteroid injection. Control animals were killed with their experimental litter-mates after being kept in the same conditions with them for the same periods. The knee joints were removed and parasagittal blocks were made of the lower femoral condyles. Fresh-frozen sections were prepared from unfixed, undecalcified material in the cryostat. The remaining tissues were fixed and decalcified by the techniques of choice for the various histochemical tests, particularly a) 10 per cent buffered 
neutral formalin (Lillie 1965) followed by 5 per cent EDTA in 10 per cent formalin (Hilleman and Lee 1953), and $b$ ) Heidenhain's "Susa" that decalcified while fixing.

After vacuum-embedding in paraffin or Steedman's Ester Wax, 1960, serial sections were made of the whole femoral condyle, to include articular and epiphysial plate cartilage, epiphysial and metaphysial cancellous trabecular bone. In addition to staining with haematoxylin and eosin, these sections were submitted to a variety of histochemical tests, including periodic acid-Schiff (PAS) alone (McManus 1954), or with alcian blue at pH 2.5 (Mowry and Winkler 1956) or at pH 1.0 (Lev and Spicer 1964, Spicer 1965); alcian blue at pH 2.5 (Steedman 1950), or at pH 5.7 in controlled electrolyte concentrations of magnesium chloride (Scott and Dorling 1965); Southgate's mucicarmine; toluidine blue (Gurr 1958), and azure A for metachromasia. Sudan black was used to test for lipids; the

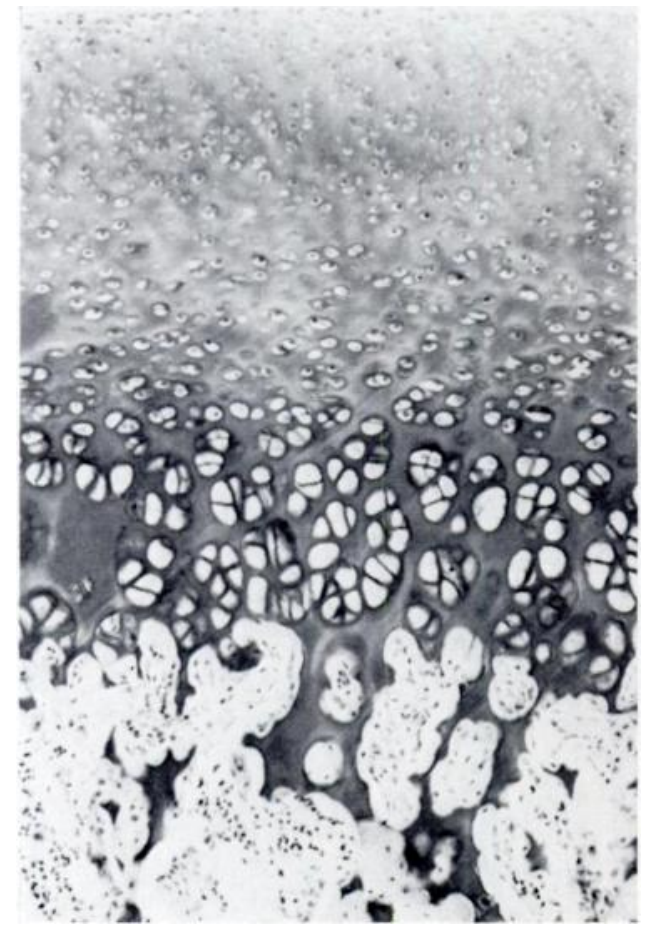

Fig. 1

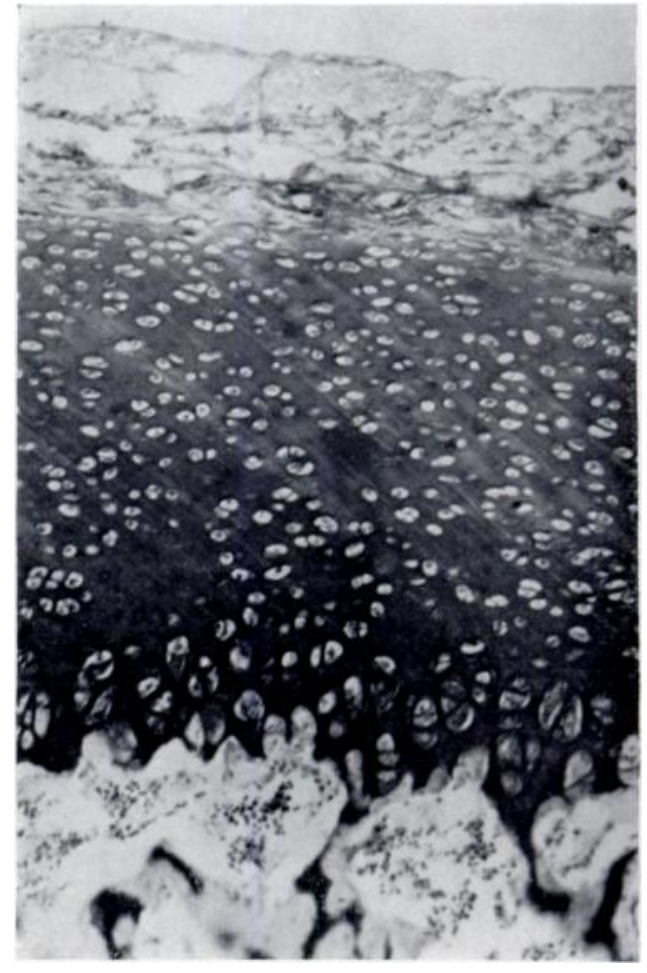

Fig. 2

Figure 1-To show the normal articular cartilage of a control rabbit. Alcian blue (pH 2.5) stains the acid sulphomucins of the matrix, and the calcified matrix between the hypertrophic cells. The calcified matrix is remodelled by osteoclasts, while osteoblasts lay down osteoid and bone to give the typical dentate appearance of subchondral ossification. $(\times 160$. $)$ Figure $2-$ To show the articular cartilage after thirteen daily intramuscular injections of cortisone. Fibrillation is seen at the surface. Acid sulphomucins are present in the matrix but the hypertrophic cells are few, and there is poor organisation of subchondral trabeculae in comparison with the control animal. (Alcian blue, $\mathrm{pH} 2 \cdot 5, \times 160$.)

coupling azo-dye method for alkaline phosphatase (Pearse 1968); methyl green-pyronin, with ribonuclease control, to distinguish RNA (Brachet 1953); orcein and Van Gieson's picrofuchsin for elastic and white fibrous tissue; and autoradiography, using Kodak AR 10 plates in a modification of Pelc's (1958) stripping film technique.

All regions of the articular cartilage and subchondral bone of the distal femoral condyles were examined microscopically.

\section{RESULTS}

Normal control group-In the normal rabbits of this weight the hyaline articular cartilage was limited by a single surface layer of flattened cells that failed to stain with alcian blue at $\mathrm{pH} 1.0$ or $2 \cdot 5$, though the cell cytoplasm showed a PAS reaction. Beneath this articular surface was a 
layer three to six cells deep of less flattened cells separated by a small amount of matrix that stained deeply with alcian blue, was PAS-positive and showed $\gamma$-metachromasia with toluidine blue.

Large areas of matrix, staining weakly with PAS, separated the oval cells of the middle zone, where alcian blue stained the matrix and perilacunar halos.

Hypertrophic cells in clusters of two to eight distinguished the basal zone. Each cell had a distinct lacunar capsule that stained vividly with haematoxylin, alcian blue, toluidine blue, aldehyde-fuchsin and Southgate's mucicarmine, but not with PAS or Best's carmine. The cell cytoplasm contained appreciable amounts of granular glycogen (Fig. 1).

Autoradiography, using sulphur-35, showed that the newly synthesised sulphated material, although occurring throughout the cartilage matrix, was most concentrated around the lacunae in the hypertrophic zone and not in the cells themselves.

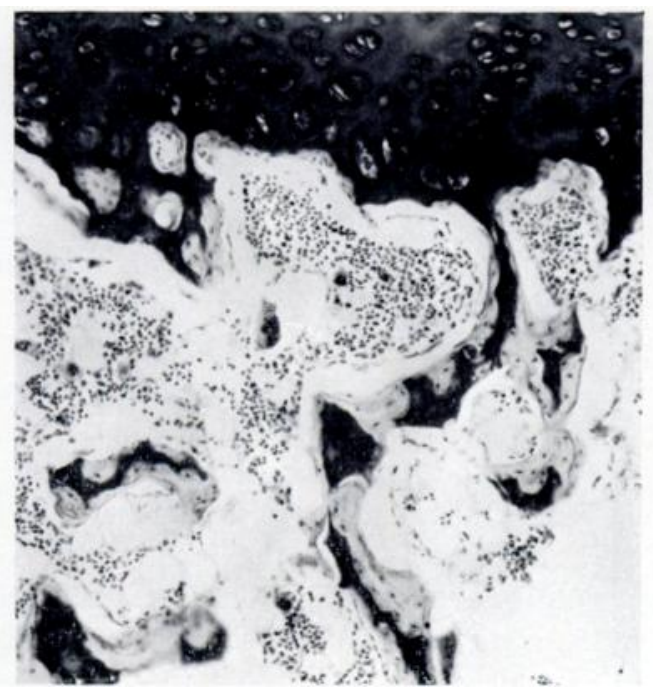

FiG. 3

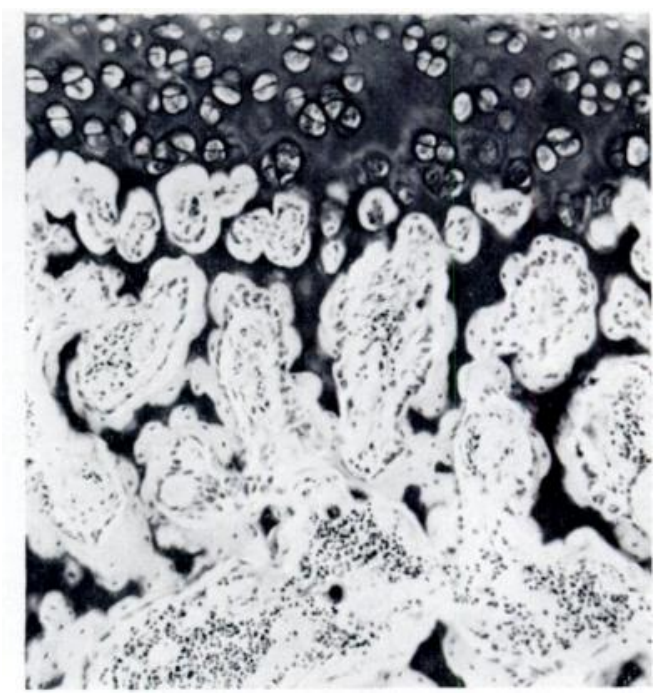

Fig. 4

Figure 3-To show subchondral ossification twelve days after intra-articular methyl prednisolone. The zone of hypertrophic cells is shallow and the calcified matrix is not remodelled in the normal dentate pattern, so there are few trabeculae that show the "hard" edges of resorbed bone. Osteoblasts are few and spindleshaped. (Alcian blue, $\mathrm{pH} 2.5, \times 160$.) Figure $4-$ To show the dentate pattern of subchondral ossification in the control animal. There are many trabeculae covered profusely with cuboid osteoblasts. (Alcian blue, $\mathrm{pH} 2 \cdot 5, \times 160$.)

The effects of corticosteroids-In the articular cartilage the matrix near the surface lost its hyaline appearance and became "fibrous", as though loss of matrix had exposed these unsupported fibres. The separate fibrils were horizontally disposed and stained pink with Van Gieson's picrofuchsin, indicating that they were collagenous. This fibrillation occurred at the articular surface after the first four days, with synovial membrane adhering to the fibrillated areas (Fig. 2).

Throughout the experiment the cartilage matrix retained its alcian blue staining component, but this appeared patchy or paler in those animals that had longer treatment. Mid-zone and hypertrophic cells contained more sudanophilic (lipid) granules than controls. PAS-alcian blue techniques showed that hypertrophic cells retained granules of both glycogen and sulphomucins. Intracytoplasmic granules of RNA were reduced.

After thirteen days the basal cells were not hypertrophic but oval like those of the mid-zone. The pattern of subchondral ossification changed, becoming flat instead of dentate (compare Figs. 3 and 4). Few trabeculae of cancellous bone were formed. A similar effect was observed 
in both knees of six animals after intra-articular injection of corticosteroid into the left knee joint only.

Autoradiography revealed progressively less sulphur-35 uptake as the experiment proceeded and it became clear that sulphated material was not incorporated into either the cells or the matrix after the first few days. However the matrix continued to stain with alcian blue, because of chondroitin sulphates within the tissue before the tracer dose. This suggests that, though the sulphomucins were not actively removed from the cartilage, their synthesis and the consequent sulphur-35 uptake became suppressed as the level of corticosteroids built up in the body.

Synovial membrane and precipitated synovial fluid stained strongly for sulphomucins, as did the cartilage cores of established cancellous bone. The subchondral trabeculae were fewer and more attenuated after corticosteroids and there was a distinct reduction in osteoblast activity compared with normal animals or those receiving papain alone.

The effects of papain-Gross changes were caused by papain within twelve hours: all cartilage in the body, elastic as well as hyaline, was so depleted that the rabbits' ears, normally stiff and upright, hung down like those of a spaniel for about three days. They became erect again as the chondroitin sulphates were replaced in the cartilage matrix. By the end of the first twentyfour hours sulphomucins were abundant in blood, bone marrow and synovial fluid. The alcian blue stain confirmed the report of Weissmann, Potter, McCluskey and Thomas (1961), who

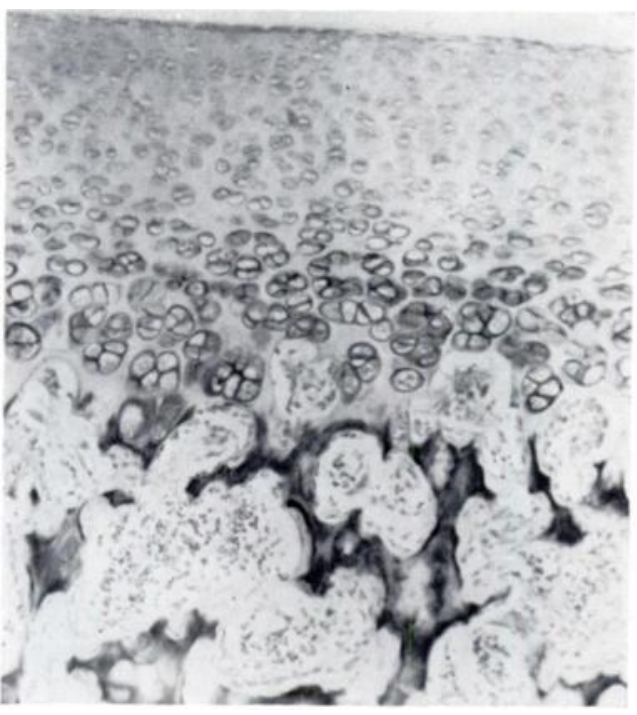

Fig. 5

Articular cartilage four days after papain. Hyaline cartilage matrix is depleted and only the calcified cartilage cores of subchondral bone trabeculae are stained. (Alcian blue, pH 2.5, $\times 160$.) demonstrated a fifty-fold increase of chondroitin sulphate in the blood after papain injection, using anti-sera techniques.

The surface of the femoral articular cartilage became fibrillated in the first day, but animals killed later in the experiment showed no fibrillation. The cartilage matrix no longer reacted with alcian blue (Fig. 5), though the cartilage cores of cancellous bone still stained brightly, protected from the action of the protease by surrounding bone. Granules staining with alcian blue and PAS were not removed from the cartilage cells; the hypertrophic cells were particularly rich in such material. Similarly, staining with Sudan black showed that intracytoplasmic granules of lipid remained.

After eight days sulphomucins reappeared in the matrix in the superficial and hypertrophic zones. Thin perilacunar halos reacted more strongly than the ground substance and also outlined mid-zone chondrocytes against an unstained matrix. The middle zone was slower to recover, perhaps because it is less open to sulphate exchange than either the hypertrophic zone with its many subchondral capillaries, or the articular surface bathed in synovial fluid (Fig. 6). As the staining reaction of the matrix was restored, the cell cytoplasm lost its alcianophilic granules, suggesting that they were discharged from the cells into the matrix to promote this recovery; granules reappeared in the cells after a week.

Papain did not remove sulphomucins from trabecular cartilage that was already surrounded by bone, but new subchondral trabeculae were formed on depleted cartilage and so had central cores that were pale, unstained with alcian blue or metachromatically with toluidine blue. As recovery proceeded, the next new cores became deeply stained as before; so the area of pale 
cores "marked" the extent of growth since the papain injection (Fig. 7). The pattern of subchondral ossification remained normal. After three weeks the articular cartilage was virtually restored to normal, except that in the middle zone the matrix still stained less than in control animals.

Autoradiography immediately after papain showed no tracer over the cartilage, but during the succeeding two weeks labelled sulphate was replaced. Twenty-two days after papain, there was more label over the hypertrophic cells themselves than in the control animals, showing that repair after papain involves increased cell uptake of sulphate for sulphomucin synthesis even as late as this.

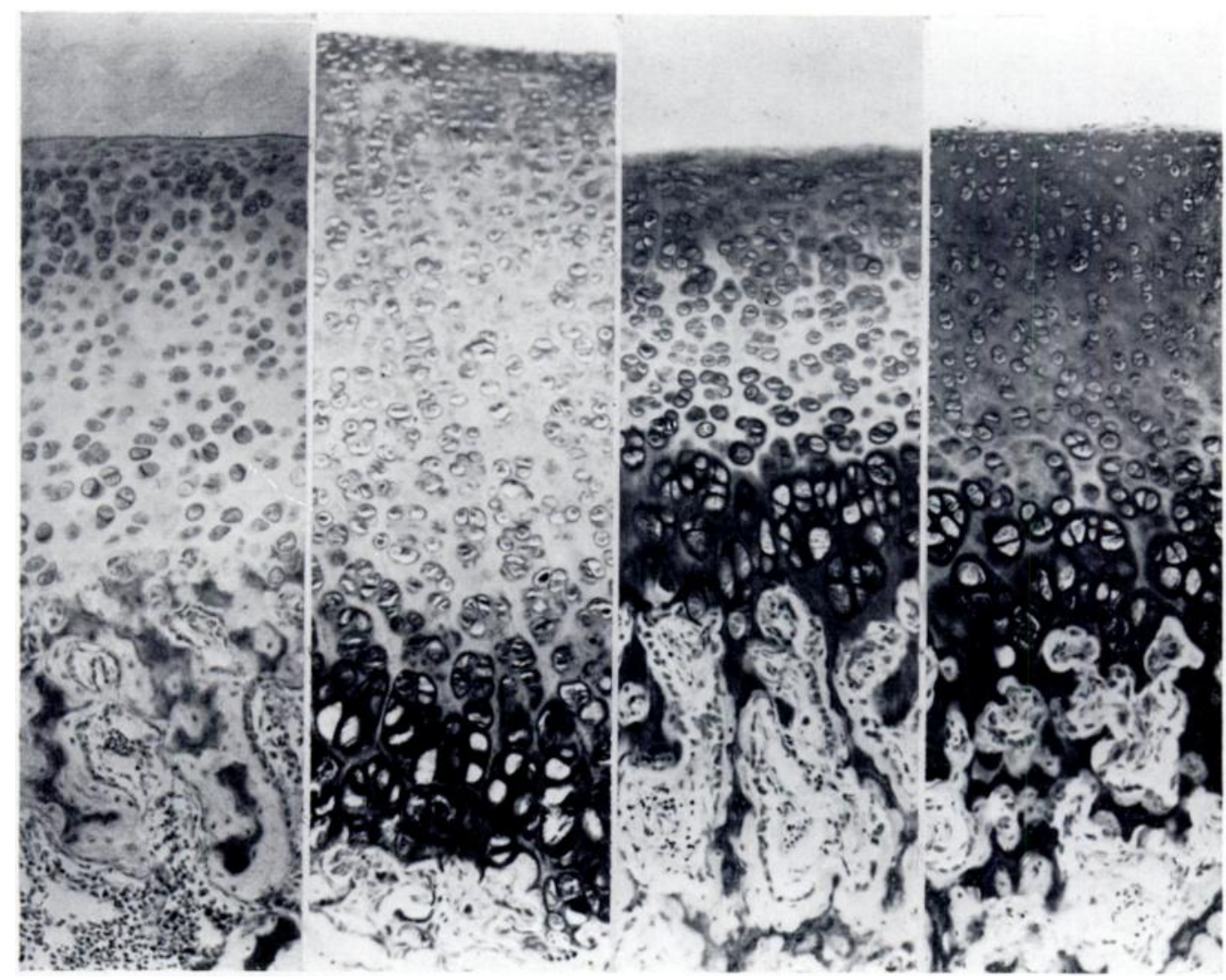

FIG. 6

Articular cartilage. A composite photomicrograph showing recovery after papain at four, eight, thirteen and seventeen days. At four days hyaline cartilage matrix contains virtually no alcianophilic material, but gradually recovers. Slow recovery of the middle zone is apparent. (Alcian blue, $\mathrm{pH} 2.5,320$.)

The effects of corticosteroids after papain-Corticosteroids delayed the recovery from the effects of papain in these rabbits: their ears remained limp for about ten days. While daily corticosteroid was given the articular cartilage matrix failed to regain its normal alcian blue staining property, but showed a progressively stronger PAS reaction. This shift in response to alcian blue/PAS techniques indicated that neutral glycoproteins were being synthesised instead of the acid sulphomucins, demonstrating inhibition of both sulphation and carboxylation.

Fibrillation of the articular surface was worse than after papain alone, and persisted throughout the experimental period (Fig. 8). As with corticosteroids alone, the cells of the basal zone remained like those of the middle zone in size and distribution, and the matrix between them failed to organise into cores of subchondral cancellous bone. The few trabeculae 
that formed on depleted cartilage remained virtually stationary in the epiphysis; this "papain marker" indicated that little growth had taken place. The seven animals that were given intra-articular corticosteroids after papain showed a similar effect in both knees, and this was commensurate with the changes observed after intramuscular corticosteroids.

Autoradiography showed no uptake of labelled sulphate after the fourth day.

\section{DISCUSSION}

We have established that if an intact animal is given daily corticosteroids its trabecular growth is retarded and bone becomes osteoporotic; the articular surface becomes fibrillated, the basal cells of the cartilage do not mature to become hypertrophic, and the pattern of the

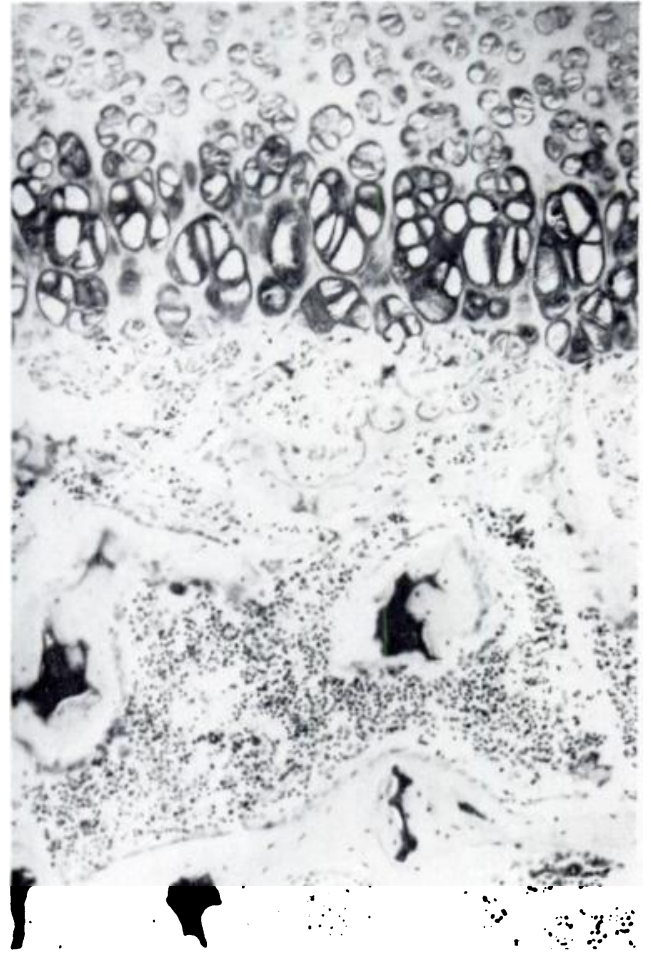

Fig. 7

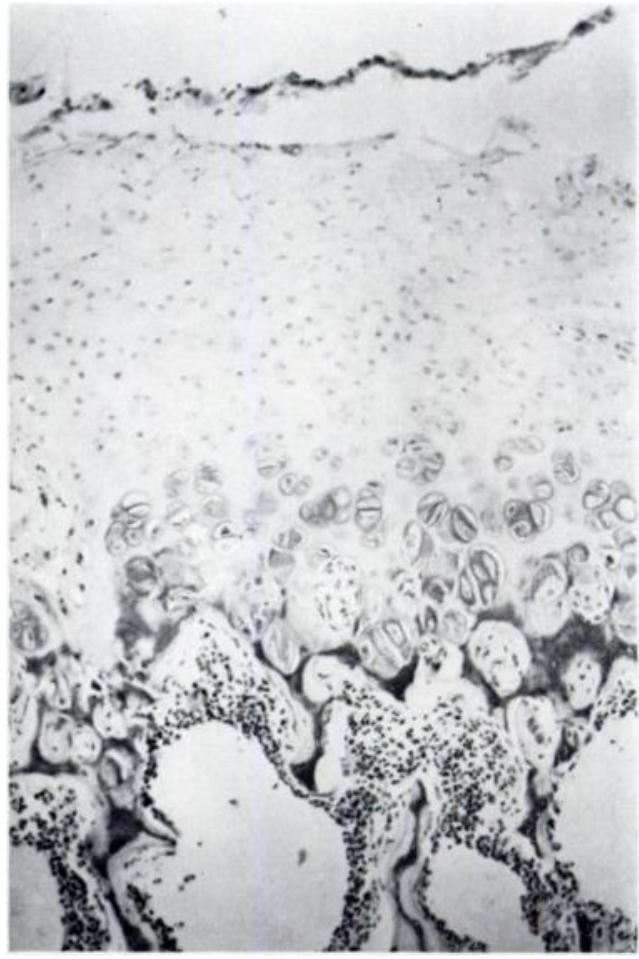

FIG. 8

Figure 7-Subchondral calcification eight days after papain. Sulphated mucopolysaccharides stain as thin rims around cartilage cells but the most recent trabecular cartilage cores have been formed from depleted cartilage and so are unstained. In contrast, the cartilage cores of bone trabeculae that were formed before the papain injection stain strongly with alcian blue at pH 2.5. $(\times 160$.$) Figure 8-Articular cartilage.$ Fibrillation is present on the surface when daily cortisone is given for thirteen days after papain. The basal cells do not become normally hypertrophic and the matrix fails to organise normally into cores of subchondral bone. (Alcian blue, $\mathrm{pH} \mathrm{2.5, \times 160.)}$

subchondral ossification into trabeculae is lost; intracytoplasmic RNA is reduced, sulphomucin synthesis is inhibited, glycogen and lipids accumulate within the cartilage cells and neutral glycoproteins accumulate in the matrix.

The loss of alcian blue stained material from cartilage matrix after injection of papain confirms the reports of Spicer and Bryant (1957) and McCluskey and Thomas (1958). This loss takes place firstly from the surface and middle zones and lastly from the deep zone, where thin rims of sulphomucin remain at twelve hours after papain, probably because of the greater concentration of these substances normally in the perilacunar halos of the hypertrophic cells. The failure of papain to remove intracytoplasmic granules staining with alcian blue, PAS and 
Sudan black has been revealed by the present study and has not been discussed by previous workers.

Staining with Van Gieson's picrofuchsin showed exposed collagen fibres in the fibrillated surface of the articular cartilage after papain. Fibrillation of articular cartilage of the femoral head of adult rabbits after prolonged injections of papain into the hip joint has recently been described by Bentley (1971) who likened the changes in the hip joint to osteoarthritis. The present studies support his findings, although they have been performed on younger animals.

The appearance of alcianophilic material in the blood vessels after papain injection is in accordance with the reports of Bryant, Leder and Stretten (1958) and Weissmann et al. (1961) who used serological techniques to demonstrate a fifty-fold increase of chondroitin sulphate in the blood after papain injection.

That basophilic material reappears first in the superficial and deep zones of cartilage matrix during recovery from papain has received little attention from other workers. The articular surface and the deep zone of the articular cartilage are supplied respectively by the mucinous synovial fluid and the abundant subchondral capillaries. We suggest that the middle zone recovers more slowly because it is remote from these sources of nutrition.

We consider that fibrillation of the articular cartilage occurs after papain alone because the collagenous framework of the cartilage matrix is no longer filled and held together by the large chondroitin sulphate molecules, and so is more vulnerable to pressure and shear stresses. In describing similar changes in the articular cartilage of rats after experimental immobilisation, Hall (1963) ascribed them to pressure effects. In the present studies, rabbits given papain alone showed fibrillation for twenty-four hours only, and then recovery took place spontaneously. This damage is not repaired in animals treated with corticosteroids after papain, and was present in the second group of animals after cortisone or methyl prednisolone alone. That fibrillation is a mechanical result of the inhibition of sulphomucin synthesis is confirmed by autoradiography showing that these animals also fail to incorporate labelled sulphate into the articular cartilage.

Layton (1951) and Bostrom and Odeblad (1953) showed that cortisone prevented the fixation of sulphur-35 as chondroitin sulphate in rats. Thomas (1956) proved that corticosteroids retarded the recovery of rabbit cartilage damaged by papain, and McCluskey and Thomas (1959) claimed that this was an exclusively local effect that could be associated with intra-articular injections. The adverse effect of intra-articular corticosteroid on the cartilage of the opposite knee joint exposes the fallacy of using such injections for local effect alone: they show a systemic action. This conclusion is supported by the work of Bain, Jacomb and Wynn (1967) who demonstrated an increase in plasma cortisol levels after intra-articular injections of corticosteroids. The opposite knee joint cannot be accepted as a "control" in assessing the effects of intra-articular injections.

Salter, Gross and Hall (1967) showed fibrillation in articular cartilage after intra-articular injections of hydrocortisone TBA, and this accords with present findings. These workers reported the appearance of cystic areas of degeneration within the middle zone of cartilage matrix. Examination of their photomicrographs suggests that these are vascular spaces (Levene 1964), and they cannot therefore be ascribed to steroids. They also found the damage to be cumulative, leading to extensive fissuring, after doses of 25 milligrams each week. The present experiments have been designed to show the progressive effects of very small doses of corticosteroids, given systemically (intramuscularly) as well as locally into one knee joint. Mankin and Conger (1966) showed that hydrocortisone TBA decreased the incorporation of glycine-3H into cartilage matrix, equating this with reduced protein synthesis.

The damage to articular cartilage by corticosteroids led to an altered pattern of development in subchondral bone. Cells at the base of the cartilage failed to become hypertrophic and there was little capillary invasion to give the characteristic normal dentate pattern. Instead, bone was laid down as a transverse plate with very few trabeculae. This tends to block metabolic

VOL. $55 \mathrm{~B}$, NO. 1, FEBRUARY 1973 
exchange between the articular cartilage and the subchondral blood vessels, and to diminish the mechanical shearing strength of this area. The paucity of the trabecular bone and of the osteoblasts themselves were further factors in the general joint damage.

The changes caused by small doses of these corticosteroids in both articular cartilage and subchondral bone of the young rabbit justify the clinical reports of damage reviewed in the introduction to this paper. The disorders may be multiple as postulated by Murray (1961)a reduction in sulphated mucopolysaccharide in articular cartilage resulting in softening and fibrillation, and inducing osteoporosis in subchondral bone. By analogy with the results after an artificial arthritis caused by papain, it must be expected that corticosteroids can retard or prevent recovery in naturally occurring joint diseases. Administration of these drugs must therefore be considered with caution.

\section{SUMMARY}

1. Because of the controversy over the clinical effects of corticosteroids on joint tissues a series of experiments on the knee joints of rabbits was undertaken.

2. The articular cartilage of the distal femoral epiphyses of normal controls has been compared with that of rabbits treated daily either with cortisone or with methyl prednisolone systemically or by intra-articular injections.

3. The changes caused by intravenous papain and their subsequent recovery have been described, and the adverse effect of corticosteroids on recovery has been assessed.

4. The biological mechanisms involved are discussed, and as a result caution is urged in the administration of corticosteroids in the presence of progressive degenerative joint disease.

We wish to thank the Research Grants Committee of the United Manchester Hospitals for supporting this work.

\section{REFERENCES}

BAIN, L. S., JACOMB, R. G., and WYNN, V. (1967): Parenteral Administration of 6a-methylprednisolone-21acetate. II. Absorption and Duration of Effect. Annals of Physical Medicine, 9, 49.

Bentley, G. (1971): Papain-induced Degenerative Arthritis of the Hip in Rabbits. Journal of Bone and Joint Surgery, 53-B, 324.

Boström, H., and Odeblad, E. (1953): The Influence of Cortisone Upon the Sulphate Exchange of Chondroitin Sulphuric Acid. Arkiv för Kemi, 6, 39.

Brachet, J. (1953): The Use of Basic Dyes and Ribonuclease for the Cytochemical Detection of Ribonucleic Acid. Quarterly Journal of Microscopical Science, 94, 1.

Bryant, J. H., Leder, I. G., and Stretten, D., Jun. (1958): The Release of Chondroitin Sulfate from Rabbit Cartilage Following the Intravenous Injection of Crude Papain. Archives of Biochemistry and Biophysics, 76, 124.

Chandler, G. N., and WrIGht, V. (1958): Deleterious Effect of Intra-articular Hydrocortisone. Lancet, 2, 661.

GuRR, E. (1958): Methods of Analytical Histology and Histochemistry. London: Leonard Hill (Books) Limited.

HALl, M. C. (1963): Cartilage Changes After Experimental Immobilization of the Knee Joint of the Young Rat. Journal of Bone and Joint Surgery, 45-A, 36.

Hilleman, H. H., and LeE, C. H. (1953): Organic Chelating Agents for Decalcification of Bones and Teeth. Stain Technology, 28, 285.

Kendall, P. H. (1958): Untoward Effects Following Local Hydrocortisone Injection. Annals of Physical Medicine, 4, 170.

Layton, L. L. (1951): Cortisone Inhibition of Mucopolysaccharide Synthesis in the Intact Rat. Archives of Biochemistry and Biophysics, 32, 224.

LEv, R., and SPICER, S. S. (1964): Specific Staining of Sulphate Groups with Alcian Blue at Low pH. Journal of Histochemistry and Cytochemistry, 12, 309.

Levene, C. (1964): The Patterns of Cartilage Canals. Journal of Anatomy, 98, 515.

Lillie, R. D. (1965): Histopathologic Technic and Practical Histochemistry. Third edition. New York: McGraw-Hill Book Company.

McCluskey, R. T., and Thomas, L. (1958): The Removal of Cartilage Matrix, in Vivo, by Papain. Identification of Crystalline Papain Protease as the Cause of the Phenomenon. Journal of Experimental Medicine, 108, 371. 
McCluskey, R. T., and Thomas, L. (1959): The Removal of Cartilage Matrix in Vivo by Papain. Prevention of Recovery with Cortisone, Hydrocortisone and Prednisolone by Direct Action on Cartilage. American Journal of Pathology, 35, 819.

McManus, J. F. A. (1954): Histochemistry of Connective Tissue. In Connective Tissue in Health and Disease, p. 31. Edited by G. Asboe-Hansen. Copenhagen: Munksgaard.

Mankin, H. J., and Conger, K. A. (1966): The Acute Effects of Intra-articular Hydrocortisone on Articular Cartilage in Rabbits. Journal of Bone and Joint Surgery, 48-A, 1383.

Mowry, R. W., and WINkLER, C. H. (1956): The Coloration of Acidic Carbohydrates of Bacteria and Fungi in Tissue Sections with Special Reference to Capsules of Cryptococcus Neoformans, Pneumococci and Staphylococci. American Journal of Pathology, 32, 628.

Moynihan, F. J. (1962): Cortisone Arthropathy. Guy's Hospital Reports, 111, 388.

MURRAY, R. O. (1961): Steroids and the Skeleton. Radiology, 77, 729.

Pearse, A. G. E. (1968): Histochemistry-Theoretical and Applied. Third edition. Volume I. London: J. \& A. Churchill Ltd.

Pelc, S. R. (1958): Autoradiography as a Cytochemical Method, with Special Reference to $\mathrm{C}^{14}$ and $\mathrm{S}^{35}$. In General Cytological Methods. Volume I. Edited by J. F. Danielli. New York: Academic Press Incorporated.

Pietrogrande, V., and Mastromarino, R. (1957): Polyostotic Fibrous Dysplasia. Osservazione sulla displasia fibrosa polyostotica con particolare riguardo alla sua evoluzione. Ortopedia e traumatologia dell'apparato motore, 25, 337.

Salter, R. B., Gross, A., and Hall, J. H. (1967): Hydrocortisone Arthropathy-An Experimental Investigation. Canadian Medical Association Journal, $97,374$.

SCOTT, J. E., and DoRling, J. (1965): Differential Staining of Acid Glycosaminoglycans (Mucopolysaccharides) by Alcian Blue in Salt Solutions. Histochemie, 5, 221.

SPICER, S. S. (1965): Diamine Methods for Differentiating Mucosubstances Histochemically. Journal of Histochemistry and Cytochemistry, 13, 211.

SPICER, S. S., and Bryant, J. H. (1957): Cartilage Changes in Papain-treated Rabbits. American Journal of Pathology, 33, 1237.

Steedman, H. F. (1950): Alcian Blue 8GS: A New Stain for Mucin. Quarterly Journal of Microscopical Science, 91, 477.

Sweetnam, D. R., Mason, R. M., and Murray, R. O. (1960): Steroid Arthropathy of the Hip. British Medical Journal, 1, 1392.

Tномаs, L. (1956): Reversible Collapse of Rabbit Ears After Intravenous Papain, and Prevention of Recovery by Cortisone. Journal of Experimental Medicine, 104, 245.

Weissmann, G., Potter, J. L., McCluskey, R. T., and Thomas, L. (1961): The Effects of Papain on Cartilage and Chondromucoprotein. Biochemical Journal, 78, 32P. 